
UC-15

Issued: March 1981

\title{
Evaluation of Savannah River Plant Shuffler Calibration Standards
}

\author{
M. M. Meier \\ T. W. Crane \\ C. J. Nachtsheim
}




\title{
EVALUATION OF SAVANNAH RIVER PLANT SHUFFLER CALIBRATION STANDARDS
}

by

M. M. Meier, T. W. Crane, and C. J. Nachtsheim

\begin{abstract}
Six chemistry and three nondestructive assay (NDA) measurements have been made to provide information on the $235 \mathrm{u}$ content of twelve standards cut from a cylinder of uranium-aluminum alloy to be used in calibrating the 252 Cf shuffler. These data have been evaluated to produce a set of uranium mass estimates and associater uncertainties for the standards by means of least squares techniques. Longitudinal fluctuation in uranium rensity is modeled, both by linear splines and by polynomials, arrit the two methods are compared. Also, a method is given for assessing the accuracy of the measurement uncertainties, initially provided.
\end{abstract}

\section{INTRODUCTION ANO SUMMARY}

A ${ }^{25}$ Cf Shuffier ${ }^{1}$ has been installed at Savannan River Plant (SRP) to measure the $235 \mathrm{U}$ content of waste and scrap generated at the reactor fuel fabrication facility. Measurements are performed by counting deiayed neutrons from fission after an interrogating ${ }^{252} \mathrm{Cf}$ source is returned to a we 1 !shielded position. Calibration standards are necessary to relate this neutroncounting response to the ${ }^{235} \mathrm{U}$ mass of the assay sample. It is the purpose of this report to describe the evaluation of such ra?ibration standards.

A set of calibration standards was fabricated at SRP from an extruded, cylindrical ingot of uranium-aluminum alloy with a nominal mass ratio of 0.3:0.7. A section, rough $7 y 40 \mathrm{~cm}$ long, was taken from the central, most uniform portion and was sliced to produce 14 disks $6 \mathrm{~mm}$ thick and 12 disks $25 \mathrm{~mm}$ thick. The disk diameters were $171 \mathrm{~mm}$. Thin (6-mm) and thick (25-mm) disks were removed in alternating fashion from sequential positiuns on the 
ingot, with thin disks taken from each end and adjacent thin disks taken from the center. Figure 1 illustrates the positioning of the disks. The thick disks were clad in aluminum with 1.3-mm wall thickness, and they serve as the calibration standards. After fabrication and cladding, each disk was weighed with a commercial scale to an accuracy of $0.1 \mathrm{~g}(0.006 \%)$. The thin disks were cut into quadrants, and two quadrants from each disk were destructively analyzed. The pair of quadrarits chosen for analysis varied in a rotating fasnion. This selection procedure is illustrated in Fig. 1. Three NDA measurements were taken from each thick disk, and four destructive analyses were performed on each thin disk (two from each quadrant). Section II describes the experimenial procedures and the data.

The evaluation problem is to combine these nine data sets to produce a best set of ${ }^{235} \mathrm{U}$ mass values and associated uncertainties for the 12 calibration disks. The problem considered here is complicated by the fact that we did not assume that the experimental uncertainties provided were necessarily precise. Thus, in conjunction with the determination of calibration mass values arid uncertainties, we give a method for adjusting measurement uncertainties so that they truly reflect variation in the measurement sets. Section II reviews this technique and other basic methodologies. Two approaches for ohtaining calibration mass estimates, involving linear and polynomial interpo ztion, are presented in Sections IV and $V$, respectively; Sec $V_{i}$ compares the two methods. Although results showed few differences in terms of actual caijbration disk mass estimates, we conclude that, in general, the polynomial methods considered lead to slight increases in both accuracy and precision.

\section{EXPERIMENTAL PROCEDURES AND RESULTS}

As mentioned in the introduction, a total of nine measurements that bear on the ${ }^{235} U$ content of each disk have been performed. At SRP one set of quadrants has been analyzed for fractional uranium content by four different chemical techniques: potentiometric analysis, modified Davies-Gray titration $(M D G)$, coulometric analysi, and isotope dilution mass spectrometry (IDMS). ${ }^{2}$ A second set of quadrants was analyzed by the group at Los Alamos National Laboratory using a LoS Alamos-automated spectrophotometer and isotope dilution mass spectrometry. ${ }^{3}$ The quadrant masses were determined at eaci laboratory by weighing. In addition, the isotopic distribution was done for each sample at Los Alamos. 


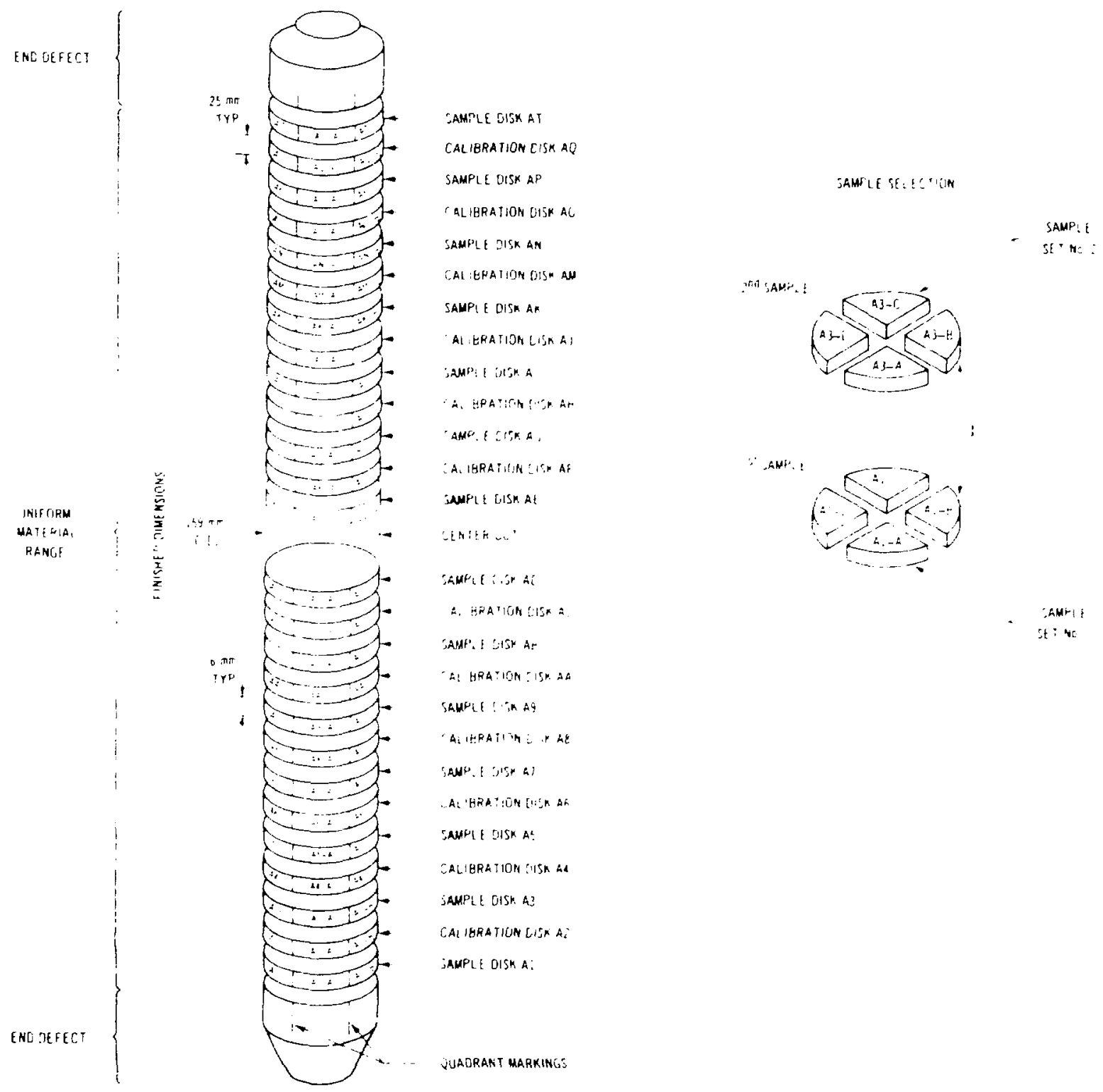

Fig. 1. Positioning of calibration and sample disks.

The Los Alamos chemistry measurements included the total mass, the uranium mass, and the uranium isotope a.stribution for each quadrant. Total mass uncertainty was less thar, $0.01 \%$ and was ignored. Uranium mass uncertainty was $0.19 \%$ and $0.26 \%$ for isotope dilution mass spectrometry and automated spectrophotometer, respectively. The ${ }^{235} U$ fraction of total uranium had an uncertainty of $0.05 \%$, which was ignored. 
The SRP chemistry results were quoted in terms of uranium fractions that were converted to ${ }^{335} \mathrm{U}$ mass fraction by use of the LoS Alamos isotopics data for oarh disk. The $0.05 \%$ uncertainties of the latter were again ignored. The incartainties asSOCiated with the SRP chemistry results were: potentiometric anulvsis, n.10\%; modified Davies-Gray titration, 0.50\%; coulometric anaiysis, 1. 30\%: and isotopo dilution mass spectrometry, 0.30\%.

Lt La. Alanos three nthor measurements were performed on the thick disks $\because$ nontestrurtive terhniques. Reilly counted the $186-k e v$ qamma rays from i arh tisk and app?ier a transmission-dependent correction to account for attenlation in the samplo. Peference 5 describes the counting of delayed neutrons after nu'red-unution interrogation by the Van de Graffe arcelerator. Finally, the Shuffler itself was user! at. SRP to produce a set of relative data for the $\because$ thilk ficke.

ine Reiliv gama-ray spertroscony data were the ?35y mass values for ath af the ?" thirk tiske. ihese were combined with the SRP weighings of these tisks to q a the ?35: nass frartion. The tota? statistiral uncertainty $\therefore$ this mets roment was affor, but observed monuniformities in the samples intrulure nfferts te which this methrid may be sens, itive. Based on his measurem.nes of variations in the transmiscion, Reilly petimates that systematic un$\therefore$ inties mav bo as high as $3 \%$. Secause the nonuniformities were similar in rtharter from rick to disk, we decifed to assign the $0.46 \%$ unrertainty to the mexs dr ement and, if necessary, treat the data set as relative.

V.un te Graaff data were quoted as $235 \mathrm{U}$ mass, and the SRP weighings were 1150 tr corvert then to $235 \mathrm{U}$ mass fraction. These data have an uncertainty of $3 \%$, the relative standard deviation of a standard analyzed concurrently with the itisks. The ratios nf Shuffler response to weighed mass for each thick disk comprise a final, relative set of data proportional to the $235 \mathrm{U}$ mass fraction. The Shuffler response has uncertainties ranging from $0.08 \%$ to $0.11 \%$.

Thus, the data to be analyzed consisted of 84 chemical and 36 NDA measurements and all associated uncertainties. For the linear interpolation analysis given in Sec. IV, three additional observations were made by interpolating each of the three pairs of NDA measurements from the adjacent thick disks. Table I gives the complete set of 120 observations, in addition to the interpolations and the weights used in the interpolations. Table I also provides uncertainty data. The relative standard deviations for each value were the same throughout each set except for the Shuffler data and are listed below 
each data set. The $r$ ange of Shuffler relative standard deviations is indicated, although in the evaluation jrocedure each measurement was associated with its specified uncertainty.

It must be emphasized that the relative standard deviations for sets 7 through 9 are for the measurement themselves, and not for the interpolated values used in the analyses. Standard deviations for the interpolated vaiues were calculated using the identity

$$
\operatorname{SO}\left(a_{\mu_{1}}+b_{\mu_{2}}\right)=\sqrt{\left[a \cdot S O\left(\mu_{1}\right)\right]^{?}+\left[b \cdot \operatorname{SD}\left(u_{2}\right) ? ?\right.}
$$

where SD represents standard deviation, $u_{i}$ is the $i^{\text {th }}$ measurement, aid a and $b$ are the weights used in the interpolation. No intorpr?ation prer was incorporated in the assigned uncertainties.

\section{BASIC ANALYSIS METHODOLOIGY}

The evaluation procedure uses the method of loast squaras de rijtined in Ref. 6. The formalism wili be briefly described here to chow the modification,s used in tred: 19 this problem and to define quantilies that will have subsequent use.

Consider J masses each measured by $A$ absolute technioues and $R$ relative techniques. Information on the $j^{\text {th }}$ mass can be ontained from the ahsolute. measurements

$$
M_{j}=\mu_{i j} \pm r_{i j} \quad i=1, ?, \ldots, A \text {, }
$$

and from the relative measurements

$$
R_{j} M_{j}=u_{i j} \pm r_{i j} \quad i=A+1, A+2, \ldots, A+R .
$$

Here $\left(\mu_{i j}{ }, r_{i j}\right)$ are the measurement values and associated uncertainties for the $j^{\text {th }}$ mass measured by the $i^{\text {th }}$ technique. Let $M_{j}$ be the best value of the $j^{\text {th }}$ mass to be determined by the evaluation and $R_{i}$ be the best value of a factor that scales the $i^{\text {th }}$ relative measurements to the absolute values. 
TABLE I

235U MASS AND UNCERTAINTY DATA

\begin{tabular}{|c|c|c|c|c|c|c|c|c|c|c|}
\hline & $\begin{array}{l}\text { Mais } \\
\because \because \quad \ldots\end{array}$ & 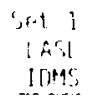 & $\begin{array}{c}\text { Set? } \\
\text { lASL } \\
\text { Autn. Spert }\end{array}$ & $\begin{array}{c}\text { set ? } \\
\text { sep } \\
\text { Potent. }\end{array}$ & $\begin{array}{c}\text { SOP } 4 \\
\text { MNPG } \\
\text { MDG }\end{array}$ & $\begin{array}{c}\text { ift } 5 \\
\text { sep } \\
\text { roulgmt. }\end{array}$ & $\begin{array}{l}\text { Set } 5 \\
\text { SRP } \\
1 D M^{-}\end{array}$ & $\begin{array}{l}\text { Sot } 7 \\
\text { LASi. } \\
\text { VQG }\end{array}$ & $\begin{array}{l}\text { Set } R \\
\text { LASL } \\
\text { Y SpeCt. }\end{array}$ & $\begin{array}{l}\text { Set } 9 \\
\text { LASL } \\
\text { Shuff ER }\end{array}$ \\
\hline$\because$ & r + ' & 16.46 & 16.46 & $16.4 t_{1}$ & ]$f_{1} . c_{2}$ & $! 6.45$ & $16.4 \%$ & & & \\
\hline$\therefore:$ & 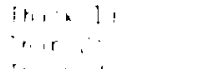 & $i 5.44$ & ?r. sit & $3 t .28$ & $\mid 1.41$ & If.,$f^{\prime}$ & 16.37 & $\begin{array}{l}17.37 \\
17.01 \text { व }\end{array}$ & $\begin{array}{l}15.9 ! \\
1: 3 \% a\end{array}$ & $\begin{array}{l}7.4 ? 5 \\
7.4738\end{array}$ \\
\hline $\begin{array}{l}\text { in } \\
\therefore \\
\text { an }\end{array}$ & 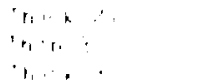 & $\therefore \therefore$ & $i i, .4$ & $i \xi_{i} . \Delta ?$ & 16.47 & In. & $1 f_{1} .10$ & $\begin{array}{l}16.115 \\
16.100 \\
16.10\end{array}$ & $\begin{array}{l}15.17 \\
12.140 \\
15.18\end{array}$ & $\begin{array}{l}\therefore 4 i \\
3490 \\
40 ?\end{array}$ \\
\hline $\begin{array}{l}\therefore ! \\
\therefore\end{array}$ & $\begin{array}{l}4 \\
1\end{array}$ & $! r_{i}, 4 r$ & $? 6.49$ & 16.44 & $.6 . .^{\prime A}$ & $16.4 \%$ & 16.48 & $\begin{array}{l}16.59 \\
16.97\end{array}$ & 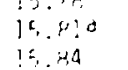 & $\begin{array}{l}3.4114 \\
3.414\end{array}$ \\
\hline $\begin{array}{l}\therefore \prime \\
\therefore ;\end{array}$ & $\begin{array}{l}r \cdot r . \\
r_{1} \cdot\end{array}$ & 16.26 & $\therefore r .4$ & $f f . f ?$ & $1 H_{1} .3$ & $! f_{1} .6^{\circ}$ & 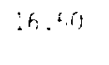 & $\begin{array}{l}: h ., 7 d \\
: 7 . n ?\end{array}$ & $\begin{array}{l}: 50 t \\
5.9 \mathrm{i}\end{array}$ & $\begin{array}{l}7.40 \%: \\
7.444\end{array}$ \\
\hline $\begin{array}{l}\therefore i \\
\therefore\end{array}$ & $\begin{array}{l}+r+ \\
n_{1}+t_{t}\end{array}$ & lh. $5 i$ & 35.53 & 1f. . F.A & If. SF, & if. 56 & $16, .69$ & $\begin{array}{l}17.04 d \\
17.77\end{array}$ & $\begin{array}{l}5.96 \mathrm{~d} \\
15, \times 1\end{array}$ & $\begin{array}{l}? .4440 \\
? .4 \%\end{array}$ \\
\hline$\therefore 1:$ & $T_{p}: P_{1}:$ & If. Les & $1 f_{1} \cdot c_{1}$ & 16.6 .9 & lh.5: & $6.6:$ & $: 6, .07$ & In. $6 ?^{h}$ & $14.93^{\circ}$ & $7.475,1$. \\
\hline$A !$ & $\begin{array}{l}\because+8 \\
\because 1+47\end{array}$ & $\because r ., 4$ & 36.5 & If . ph & if . fit. & if... & $\therefore+. A P$ & $\begin{array}{l}\text { i6. } 45 r \\
16.01\end{array}$ & $\begin{array}{l}15.90 \% \\
15,9,3\end{array}$ & $\begin{array}{l}? .477^{r} \\
? .464\end{array}$ \\
\hline $\begin{array}{l}\cdots \\
\therefore \cdots\end{array}$ & 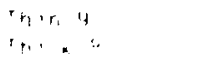 & 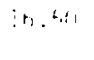 & $\because .94$ & $: F_{3} .2 .1$ & !h. & $\therefore n_{n}, n$ & $i+\ldots$ & $\begin{array}{l}15.43 a \\
: 5.46\end{array}$ & $\begin{array}{l}14.190 \\
15.73\end{array}$ & $\begin{array}{l}7.46 !^{J} \\
7.45 \%\end{array}$ \\
\hline$\therefore$ & $\begin{array}{l}\because 4 \\
\cdots, 4\end{array}$ & $\therefore \therefore$ & $\therefore .4$ & $\therefore t .6$. & $\therefore$. & $! f_{.} .44$ & $\therefore 5.15$ & $\begin{array}{l}35.548 \\
15.21\end{array}$ & $\begin{array}{l}15.850 \\
15.96\end{array}$ & $\begin{array}{l}2.4 E^{3}{ }^{3} \\
2.464^{4}\end{array}$ \\
\hline & $\because \quad \vdots \vdots$ & $\therefore \therefore:$ & $?+.4:$ & $\therefore .4$. & 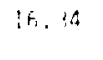 & $? f_{1}, L ;$ & Iń. 4 & $\begin{array}{l}16.5^{7 d} \\
3.13\end{array}$ & $\begin{array}{l}5.90^{d} \\
: 5.83\end{array}$ & $\begin{array}{l}7.474^{3} \\
2.46^{5}\end{array}$ \\
\hline $\begin{array}{l}\therefore \\
\therefore\end{array}$ & $\begin{array}{l}\ddots \\
\ddots\end{array}$ & 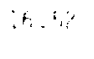 & $16.4 ?$ & $: 6.4$ & 17.55 & $i k_{3} . A 6$ & 'b. 45 & $\begin{array}{l}11.16^{a} \\
17.19\end{array}$ & $\begin{array}{l}{[6, .8]^{d}} \\
6.91\end{array}$ & $\begin{array}{l}? .46 F \bar{a} \\
? .468\end{array}$ \\
\hline & $\begin{array}{ll}1 & 3 \\
0 & 0\end{array}$ & $\therefore .4 F$ & ]h. A: & $3, .4^{2}$ & !h. $3^{\circ}$ & $i r . A \varphi$ & $\therefore 0 . \therefore$ & $\begin{array}{l}15.67^{9} \\
15.96\end{array}$ & $\begin{array}{l}\because .89 a \\
1=.45\end{array}$ & $\begin{array}{l}2.468 \mathrm{~A} \\
2.469\end{array}$ \\
\hline$\therefore$ & $\therefore \quad: 1$. & $\because t$. & $\therefore 6.41$ & $\mid F_{1} . L_{i}:$ & $i f, r_{i}$ & if.then & $56.2 h$ & & & \\
\hline & 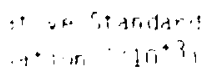 & $\therefore 4$ & $2 . t$ & 1.6 & 5.11 & 3.0 & $\therefore 1$ & 3,5 & A. & 1). $7-i$. \\
\hline & 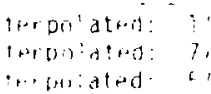 & 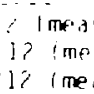 & rement of & $\begin{array}{l}\text { Ck disk } \\
\text { ick lisk } \\
\text { ick disk }\end{array}$ & $\begin{array}{l}\text { hove) " } \\
\text { aloovel } \\
\text { abnues: }\end{array}$ & $\begin{array}{l}\text { 1? tmeds } \\
511 ? \text { line } \\
\text { 1/1? tme }\end{array}$ & suramen & $\begin{array}{l}\text { thick } \\
\text { of thirk } \\
\text { of thirk }\end{array}$ & $\begin{array}{l}\text { sk be low i } \\
\text { disk belo } \\
\text { disk bela }\end{array}$ & ). \\
\hline
\end{tabular}

Because of the product term, $R_{i} M_{j}$, adove, nonlinear least squares mothodology is required to obtain best estimates $M_{j}$ and $R_{j}$ of the parameters $M_{j}$ and $R_{i}$. Let $M_{j}^{0}$ be an estimate (for example, a weighted average of absolute measurements) of the best mass value for the $j$ th mass, and let $R_{i}^{0}$ be an estimate of the best scale factor for the $i^{\text {th }}$ measurement tecnnique. Then, using a Taylor expansion of the product term, normalized residuals for each measurement are

$$
r_{i j}=\left[\frac{\Delta M_{j}}{M_{j}^{O}}-\frac{\Delta \mu_{i j}}{M_{j}^{O}}\right] \sigma_{i j}-1 \quad i=1,2, \ldots, A
$$

and 


$$
r_{i j}=\left[\frac{\Delta M_{j}}{M_{j}^{O}}+\frac{\Delta R_{i}}{R_{i}^{O}}-\frac{\Delta u_{i j}}{R_{i}^{O} M_{j}^{O}}\right]{ }_{i j}-1 \quad i=A+1, A+2, \ldots, A+R \text {. }
$$

where

$$
\begin{aligned}
\Delta M_{j} & =\dot{M}_{j}-M_{j}^{O} \\
\Delta u_{i j} & =u_{i j}-\dot{R}_{i} M_{j}^{O} \\
\Delta R_{i} & =\dot{R}_{i}-R_{i}^{O} .
\end{aligned}
$$

The best masses and scale factors are the values for which the sum of squares of residuals is minimized:

$$
\begin{aligned}
& \frac{2}{\partial M}{ }_{j \prime} \sum_{i=1}^{A+R} \sum_{j=1}^{j} r_{i j}{ }^{2}=0 \quad j^{\prime}=1,2, \ldots, j, \\
& \frac{\partial}{\partial R_{i}} \sum_{i=A+1}^{A+R} \sum_{i=1}^{j} r_{i j}^{?}=0 \quad i^{\prime}=A+1, A+?, \ldots, A+R .
\end{aligned}
$$

This gives rise to a set of $J+R$ equations linear in the $J$ variables $M_{j}$ and the $R$ variables $R_{;}$that are amenable to solution by matrix inversion. For increased precision, solution variables: $M_{j}:$ and $: R_{i}$ may be used as new sets of estimates: $M_{j}^{0}$ and $R_{i}^{0}$ : and the above process repeated until $\varepsilon=\ddot{j}\left(M_{j}-M_{j}^{0}\right)^{2}+\ddot{i}\left(R_{i}-R_{j}^{0}\right)^{2}$ is sufficiently small. (in general, for the data $j^{j}$ set under study, four iterations were sufficient to cause $\varepsilon$ to drop below $10^{-10} .1$

The best values, $M_{j}$ and $R_{j}$, for the variables can then be explicitly reinserted into the expressions for $r_{i j}$, and the total weighted sum of squares computed:

$$
x^{2}=\sum_{i=1}^{A+R} \sum_{j=1}^{J} r_{i j} ?
$$


An overall estimate of variance is given by

$$
B^{2}=x^{2} /[N-(J+R)]
$$

where $N$ is the total number of data points and $N-(J+R)$ is the number of degrees of freedom. The standard deviation, $B$, is referred to as the generalized Birge ratio in Ref. 6. Taylor ex al. (Ref. 6) define another parameter, $b_{i}$, which has a magnitude related to the compatibility of the $i^{\text {th }}$ data set with the others evaluated.

$$
b_{i}^{2}=\left(\sum_{j=1}^{J} r_{i j}^{2}\right)\left[n_{i}-\frac{n_{i}}{N}(J+R)\right]^{-1},
$$

where $n_{i}$ is the number of data points in the $i$ th measurement set.

If all experimenters have assessed their uncertainties correctly, each of $E^{2}, b_{1}^{2}, \ldots, b_{A+R}^{2}$ should be approximately 1 . If this is not the case, the evaluator is confronted with the problem of modifying the input data or the results to produce best mass vaulues and uncertainties consistent with the discrepant data. No well-defined procedures seem to exist for achievement of such conservative uncertainty estimates. The optimum solution, of course, would be to become intimately enough acquainted with the details of each experment to be able to assess their unceriainties in an evenhanded fashion. Such a proceaure would imply a level of aciluaintance with the experiment at least equal to that of the experimenter. Even if possible, such a method would be extremely time-consuming and cumbersome.

Some evaluation procedires, notably those that generate best values for the fundamental constants, ${ }^{6}$ tend to favor inclusion of compatible data sets. Sets that are descrepant with the main body of data have a higher probability of rejection. As a result of this procedure, the best value of a fundamental constant may change by several standard deviations in a subsequent evaluation. (See, for example, Fig. 1, p. 7, Ref. 6.) Because further evaluations could not be expected, it was felt that a more conservative approach to the assignment of uncertainties was necessary.

Actually, if for some $i, b_{i}^{2}$ is much larger than 1 , it indicates that the uncertainties associated with the $i^{\text {th }}$ data set have been underestimated by a factor of $b_{i}$. Thus, a simple, compromise procedure is to multiply the 
uncertainties associated with the $i^{\text {th }}$ data set by the value $k_{j}$, where the constant, $K$, is chosen to give $B \approx 1$. In this way, as noted in Sec. I, the method chosen for adjusting uncertainties appropriately reflects uncertainty in the data.

Without detailing the mathematics, we note that in addition to best mass values, $\hat{M}_{j}$, the least squares analys is produces a $(J+R)$ by $(J+R)$ matrix $\Sigma$ from which estimates of their variances and covariances are obtained. If the parameter estimates, $\hat{M}_{1}, \ldots, \hat{M}_{J}, R_{1}, \ldots, R_{R}$, are clenoted $P_{1}, \ldots, P_{J}+R$, then the $(i, j)^{\text {th }}$ entry of $C=B{ }^{2}$. gives the estimated covariance of $P_{i}$ and $P_{j}$. For $i=j, C_{i j}$ is simply the estimated variance of $P_{i}$. The matrix $C$ is needed, in particular, ior determining standards uncertainties. For later reference, we note that the variance of any linear combination, $\sum_{i=1}^{J+R} a_{i} p_{i}$, of the parameters is given by

$$
\operatorname{Var}\left(\sum_{i=1}^{J+R} a_{i} p_{i}\right)=\sum_{i=1}^{j+R} \sum_{j=1}^{j+R} a_{i} c_{i j} a_{j} .
$$

\section{A FIRST APPROACH: LINEAR INTERPOLATION}

A. Method

Determination of best mass and uncertainty estimates for the calibration standards is accomplished in two stecs. We first obtain uranium fraction and associated uncertainties for each of the 14 thin disks. Calibration disk masses are subsequently based on the simple linear interpolation or averaging of adjacent thin disk best mass values. Thin disk estimates are based on the 84 destructive analyses and the 36 interpolated NDA measurements. Because correlations in the data arise from interpolating thick disk values, generalized least squares procedures are required.

Briefly, the modification to the weighted least squares methodology already described is as follows. Let the unnormalized residuals, $r_{i j}{ }^{\prime}=r_{i j} \sigma_{i j}$, for the $N$ observations be denoted $e_{1}, \ldots, e_{N}$ and let the covariance of $e_{i}$ and $e_{j}$ be given by $v_{i j}$. The variance of $e_{i}$ is $v_{i j}$. Best masses are chosen to minimize $e^{\prime} v^{-1} \underset{\sim}{e}$, where $e^{\prime}=$ $\left(e_{1}, \ldots, e_{n}\right)$. In the foregoing, $v_{2}$ was simply a diagonal matrix with nonzero elements composed of the $\sigma_{i j}^{2}$. Because correlations exist, $V$ is 
no longer diagonal. For the generalized analysis, both an estimated variance, $\mathrm{s}^{2}$, and the square of the Birge ratio, $\mathrm{B}^{2}$, must be computed. This is necessary because $B^{2}$ now on $1 y$ approximates the estimated variance,

$$
s^{2}=e^{\prime} v^{-1} \text { e/ }[N-(J+R)]
$$

Previously, it was possible to partition $x^{2}$ into $A+R$ sums, $x_{i}^{2}=\sum_{j} r_{i j}^{2}$, $i=1,2, \ldots, A+R$. The expression $b_{j}^{2}$ was defined as $?_{j}^{2} /\left\{n_{i}-\left(n_{j} / N\right)(J+R)\right\}$. For the generalized analysis, such a partitioning of $\mathbf{e}^{\prime} v^{-1} e$ is not possible and, therefore, $b_{i}^{2}$ values computed will also be approximate.

B. Evaluation

The data of Table I were first inspected for consistency and biases. A calculation with all the data gave the results listed as Run A of Table II. The $b_{i}^{2}$ values indicate that sets $3,4,6$ and 8 were the most discrepant. Examination of the residuals revealed that the 12 th observation in Set 4 was somewhat aberrant. A T-test at the 0.01 level of significance rejected the case as an outlier. Deletion of the point led to an $87 \%$ reduction in the value of $t_{4}^{2}$.

The largr b value associated with data Set 8, the gamma spectroscopy measurement, was not wholly unanticipated. As mentioned in Sec. II, large systematic errors could have been introduced by the sample nonuniformities, al though there is reason to suspect that they would act in the same way for a)l the sampies. It was therefore decided to retain Set 8 unaltered but to use it as a relative data set and to delete the outlier of Set 4 for subsequent calculations. With these two changes the results labeled Run $B$ were obtained. The value of $R_{8}$ was 0.9595 , indicating a $4 \%$ bias in the Set 8 data.

Next, a series oi zalculations was done in which each absolute data set was permitted to be relative. This was done to seek out biases associated with any given measurement technique. Scaie factors and values for $B$ are listed under Run $C$ for each absolute data set given relative status. Inspection indicates that there are no gross biases and that to account for the large value of $B^{2}$ one must assume that the uncertainties of one or more data sets are underestimated. 
TABLE II

EVALUATION SUMMARIES FOR THE LINEAR INTERPOLATION ANALYSES

\begin{tabular}{|c|c|c|c|c|c|c|c|}
\hline \multirow{2}{*}{$\begin{array}{c}\text { Data set } \\
\text { i i }\end{array}$} & \multirow{2}{*}{$\begin{array}{c}\text { Run } A \\
b_{i}^{2}\end{array}$} & \multirow{2}{*}{$\frac{R \operatorname{sun} B}{b_{i}^{2}}$} & \multicolumn{2}{|c|}{ Run $\mathrm{C}$} & \multirow{2}{*}{$\frac{R u n D}{D_{i}^{2}}$} & \multirow[b]{2}{*}{ Scale Fartar } & \multirow{2}{*}{$\begin{array}{r}Q_{1, r} 5 \\
r^{2} \\
--{ }^{2}\end{array}$} \\
\hline & & & $R_{i}$ & $\mathrm{~g}^{2}$ & & & \\
\hline$]$ & 2.57 & 3.88 & 0.9982 & 4.68 & $3.4 ?$ & $\therefore .93$ & 1.0 \\
\hline 2 & $? .88$ & 3.85 & 0.9967 & $4.5 \mathrm{~F}$ & 3.99 & 1.95 & $r .5 k$ \\
\hline 3 & 9.54 & 6.40 & 1.0020 & 4.53 & 7.70 & $\therefore 7^{h}$ & $\therefore 24$ \\
\hline 4 & $i 6.59$ & 2.70 & 0.3951 & 4.66 & - & (deleted) - & \\
\hline 5 & $2.6]$ & 2.40 & 1.2007 & 4.8: & 2.3 & 1.63 & $\therefore{ }^{\prime}$, \\
\hline 6 & 17.46 & 16.97 & 1.0015 & 4.78 & - & (deleted) - & \\
\hline 7 & 0.87 & 0.77 & 1.0105 & 4.78 & $r . A r$ & $\therefore e=$ & $\therefore \cdots$ \\
\hline$\varepsilon$ & 169.40 & 1.23 & & & $\therefore x$ & $\therefore \therefore=$ & $\therefore \therefore$ \\
\hline 9 & 13.42 & 12.70 & & & 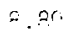 & $\therefore 9=$ & $\therefore r$ \\
\hline$e^{2}$ & $24.4 C$ & $5.6 \hat{~}$ & & & 4.2 & & $\therefore ?$ \\
\hline var:aricel & 19.97 & 4.98 & & & $\therefore \therefore$ & & $\therefore$ \\
\hline
\end{tabular}

At this point the SRP group was contacted and queried regarding the Set 4 outlier and large $b_{i}$ value for set 6 . These results were apparently not surprising in view of the procedures followed for these two analyses. As a result of this discussion, it was agreed to omit Set 4 and Set 6 from subsequent evaluation. Run $D$ of Table II gives the $b_{i}$ values for the data base, excluding Sets 4 and 6 .

Wer $a$ the data not discrepant, as indicated by $B^{2}$ values significantly larger than 1, tre evaluation would be complete, with the variance-covariance matrix specifying each mass uncertainty. Such is not the case, and the uncertainties for each data set must be adjusted using the procedure described in Sec. III. Each uncertainty for the $i^{\text {th }}$ data set was multiplied by 0.985 $\mathrm{b}_{i}$, and a reanalysis performed. The results are listed as Run E of Table II.

Table III lists mass values and relative uncertainties for each of Runs $A$ through $E$ as found by the generalized least squares analysis. The value of $\hat{\sigma}_{j}^{2}$ is given by the $i^{\text {th }}$ diagonal element of the variance-covariance matrix, listed ir. Table IV, and estimates the variance of the $i^{\text {th }}$ mass estimate, $\hat{M}_{i}$. The relative uncertainty is then $\hat{\sigma}_{i} / \hat{M}_{i}$. Notice that the 


\begin{tabular}{|c|c|c|c|c|c|c|c|c|}
\hline & \multicolumn{2}{|c|}{ Run A } & \multicolumn{2}{|r|}{ Run 8} & \multicolumn{2}{|c|}{ Run 0} & \multicolumn{2}{|c|}{ Run $E$} \\
\hline $\begin{array}{l}\text { Masc } \\
\text { !umber }\end{array}$ & $\left.M_{j} I^{\prime \prime}\right)$ & $\begin{array}{l}\text { Uncertainty } \\
\left.\mathrm{j}_{\mathrm{j}}(x) \mathrm{N}^{2}\right)\end{array}$ & $\begin{array}{l}\text { Mass } \\
M_{j}{ }^{*} \text { ! }\end{array}$ & $\begin{array}{l}\text { Tincertainty } \\
\left.\mathrm{j}_{\mathrm{j}} / \mathrm{M}_{\mathrm{j}}(x]\right)^{-?} \text { ) }\end{array}$ & $\begin{array}{l}M+5 s \\
M ! 2)\end{array}$ & $\begin{array}{l}\text { Uncertainty } \\
{ }_{j} / \dot{M}_{j}\left(\times 10^{-2}\right)\end{array}$ & $\begin{array}{l}\text { Mass } \\
M_{j}(\because)\end{array}$ & $\begin{array}{l}\text { Uncertainty } \\
\left.\bar{a}_{j} / \dot{M}_{j}(x) 0^{-2}\right)\end{array}$ \\
\hline (j) & & & & & & & & \\
\hline l & 15.47 & $0.3 n$ & 16.47 & 0.17 & 16.48 & 0.15 & 16.47 & 0.1809 \\
\hline$\because$ & 15.50 & 0.19 & $15.5 ?$ & 0.11 & if 5 ? & 0.095 & 16.52 & 0.1218 \\
\hline i & 15.47 & 0.17 & 16.19 & 0.10 & $16.5 n$ & 0.086 & 16.49 & 0.1108 \\
\hline 4 & 15.49 & 0.18 & 16.51 & 0.10 & $16 . c^{\circ} \%$ & 0.089 & 16.52 & 0.1127 \\
\hline 4 & 15.57 & 0.18 & 15.59 & 0.10 & 16.59 & 0.091 & 16.58 & 0.1157 \\
\hline f & is. 6 ? & 0.17 & 16.53 & 0.10 & 16.63 & 0.087 & $16.6 ?$ & 0.1117 \\
\hline ? & 16.59 & 0.16 & 15.51 & 0. () & 16.60 & 0.078 & 16.58 & 0.0987 \\
\hline$=$ & $: 5.58$ & 0.16 & 15.59 & $0.09 ?$ & 15.58 & ก.080 & 16.56 & 0.1005 \\
\hline 9 & 16.50 & 0.18 & 16.51 & 0.10 & 16.50 & 0.088 & 16.48 & 0.1123 \\
\hline$\vdots$ & $: \bar{a} . a 6$ & 0.18 & 16.48 & 0.10 & 15.47 & 0.1990 & 16.46 & $0.11=3$ \\
\hline$\cdots$ & 16.05 & 0.19 & 15.74 & 0.11 & 16.47 & 0.094 & 16.47 & 0.1183 \\
\hline$\because$ & if.45 & 0.19 & 16.46 & 0.11 & 16.47 & 0.095 & 16.48 & 0.1200 \\
\hline 13 & 16.47 & 0.19 & 16.49 & 0.11 & 16.49 & 0.095 & 16.49 & 0.1197 \\
\hline : & 16.50 & 0.30 & 16.50 & 0.17 & If. 54 & 0.15 & 16.54 & 0.1809 \\
\hline
\end{tabular}

sensitivity of the hest mass values to the selected evaluation technique is quite low. The largest mass variation for all techniques is only $\pm 0.09 \%$ Also, for runs of interest, $B, D$ and $E$, uncertainty estimates are quite stable. However, it is felt that the use of the uncertainty scalings in Run $E$, as based on the discrepancy indicators $b_{i}^{2}$ in $R$ un $D$, has resulted in more realistic ascessments of uncertainties. As a result, the mass estimates $\therefore M_{j}$ produced by Run $E$ are the recommended set of best values.

The calibration disk masses, $M_{j}^{c}$ and associated relative uncertainties, ${ }_{j}^{C} / M_{j}^{c}, j=1, \ldots, 12$, as based on the results of Run $E$, are listed in thle $V$. The following formulae were used in their calculation.

$$
\begin{aligned}
& M_{j}^{C}=\frac{1}{2}\left(\hat{M}_{j}+\hat{M}_{j+1}\right) ; \quad j=1, \ldots, 6 . \\
& M_{j}^{C}=\frac{1}{2}\left(\hat{M}_{j+1}+\hat{M}_{j+2}\right) ; \quad j=7, \ldots, 12 .
\end{aligned}
$$

The uncertainties were calculated using the variance-covariance matrix of the 14 best thin disk mass values (Table IV) and Eq. (1) of Sec. III. To facilitate calibration of the Shuffler at various levels of scrap mass and 
TABLE IV

VARIANCE-COVARIANCE MATRIX OF THIN OISK MASS ESTIMATESA

\begin{tabular}{|c|c|c|c|c|c|c|c|c|c|c|c|c|c|c|c|}
\hline & & $I$ & 2 & 3 & 4 & 5 & 6 & 7 & 8 & 9 & 10 & 11 & 12 & 13 & 14 \\
\hline & 1 & 8.8786 & 0.0000 & 0.0000 & 0.0000 & 0.0000 & 0.0000 & 0.0000 & 0.0000 & 0.0000 & 0.0000 & 0.0000 & 0.0000 & 0.0000 & 0.0000 \\
\hline & 2 & 0.0000 & 4.0466 & 1.5655 & 0.2094 & 0.3927 & 0.3366 & 0.2913 & 0.2748 & 0.3004 & 0.3957 & 0.3459 & 0.2518 & 0.4610 & 0.0000 \\
\hline & 3 & 0.0000 & 1.5665 & 3.3366 & 1.3849 & 0.0734 & $0.382 j$ & 0.2544 & 0.2468 & 0.2796 & 0.3645 & 0.3175 & 0.2260 & 0.4265 & 0.0000 \\
\hline & 4 & 0.0000 & 0.2094 & 1.3849 & 3.4636 & 1.6995 & -0.0360 & 0.3268 & 0.2774 & 0.2454 & 0.3591 & 0.3071 & 0.2218 & 0.4125 & 0.0000 \\
\hline & 5 & 0.0000 & 0.3927 & 0.0734 & 1.6995 & 3.6839 & 1.6619 & -0.0585 & 0.0777 & 0.3209 & 0.2794 & 0.2685 & 0.1930 & 0.3510 & 0.0000 \\
\hline & 6 & 0.0000 & 0.3366 & 0.3823 & -0.0360 & 1.6619 & 3.1 .489 & 1.3951 & 0.7624 & -0.1504 & 0.3957 & 0.2478 & 0.1974 & 0.3533 & 0.0000 \\
\hline \multirow[t]{8}{*}{$i$} & 7 & 0.0000 & 0.2913 & 0.2544 & 0.3268 & -0.0585 & 1.3951 & 2.6840 & 2.4470 & 0.8458 & 0.0955 & 0.2502 & 0.1496 & 0.2974 & 0.0000 \\
\hline & 8 & 0.0000 & 0.2748 & 0.2468 & 0.2774 & 0.0777 & 0.7624 & 2.4470 & 2.7767 & 1.4952 & -0.0752 & 0.2707 & 0.1336 & 0.2835 & 0.0000 \\
\hline & 9 & 0.0000 & 0.3004 & 0.2796 & 0.2454 & 0.3209 & -0.1504 & 0.8458 & 1.4952 & 3.4 .320 & 1.6343 & -0.0388 & 0.2477 & 0.2837 & 0.0000 \\
\hline & 10 & 0.0000 & 0.3957 & 0.3645 & 0.3591 & 0.2794 & 0.3957 & 0.0955 & -0.0752 & 1.6343 & 3.6012 & 1.3977 & -0.1015 & 0.4911 & 0.0000 \\
\hline & 11 & 0.0000 & 0.3459 & 0.3175 & 0.3071 & 0.2685 & 0.2478 & $0.250 ?$ & 0.2707 & -0.0388 & 1.3977 & 3.7995 & 1.7483 & -0.0788 & 0.0000 \\
\hline & 12 & 0.0000 & 0.2518 & 0.2260 & 0.2218 & 0.1930 & 01974 & 0.1496 & 0.1336 & 0.2477 & -0.1015 & 1.7483 & 3.9106 & 1.6619 & 0.0000 \\
\hline & 13 & 0.0000 & 0.4610 & 0.4265 & 0.4125 & 0.3510 & 0.3533 & 0.2974 & 0.2835 & 0.2837 & 0.4911 & -0.0788 & 1.6619 & 3.8975 & 0.0000 \\
\hline & 14 & 0.0000 & 0.0000 & 0.0000 & 0.0000 & 0.0000 & 0.0000 & 0.0000 & 0.0000 & 0.0000 & 0.0000 & 0.0000 & 0.0000 & 0.0000 & 8.9619 \\
\hline
\end{tabular}

aThe $(i, j)^{\text {th }}$ entry gives the $\operatorname{Cov}\left(\dot{M}_{i}, \dot{M}_{j}\right) . \operatorname{Cov}\left(M_{i}, \dot{M}_{j}\right)=\operatorname{var}\left(\dot{M}_{i}\right)$. Each entry must be multiolieo by $10-4$. 


\section{TABLE $V$}

LINEAR INTERPOLATION ANALYSIS (RUN E) CALIBRATION DISK MASS AND UNCERTAINTY FSTIMATES

\begin{tabular}{|c|c|c|c|c|c|}
\hline ?isk & $\begin{array}{c}\text { Total } \\
\text { Mass } \\
\text { (g) }\end{array}$ & $\begin{array}{c}\text { Percen tage } \\
\text { Ur an ium }\end{array}$ & $\begin{array}{c}\text { Mass } \\
\text { Ur an ium } \\
(g) \\
\end{array}$ & $\begin{array}{c}\text { Uncertainty } \\
(\mathrm{g})\end{array}$ & $\begin{array}{c}\text { Relative } \\
\text { Uncertainty } \\
\left(\times 10^{-3}\right) \\
\end{array}$ \\
\hline 1 & 1671.13 & 16.494 & 275.64 & 0.30040 & 1.090 \\
\hline$=$ & 1680.62 & 16.501 & 277.32 & 0.27250 & 0.983 \\
\hline 3 & 1656.62 & 16.496 & 274.92 & 0.25779 & $0.93 \%$ \\
\hline 4 & 1646.30 & 16.546 & 272.39 & 0.26732 & 0.981 \\
\hline 5 & 1675.13 & 16.606 & 278.18 & 0.27084 & 0.974 \\
\hline 6 & 1674.66 & 16.613 & 278.21 & 0.25012 & 0.899 \\
\hline$?$ & 1664.47 & 16.537 & 275.25 & 0.25242 & 0.917 \\
\hline 8 & 1673.58 & 16.479 & 275.78 & 0.26858 & 0.974 \\
\hline 9 & 1678.23 & 16.467 & 276.35 & 0.26794 & 0.970 \\
\hline 10 & 1674.02 & 16.472 & 275.74 & 0.28020 & 1.012 \\
\hline 11 & 1675.35 & 16.480 & 276.11 & 0.27948 & 1.012 \\
\hline 12 & 1672.86 & 16.517 & 276.31 & 0.29994 & 1.086 \\
\hline
\end{tabular}

volume, Table VI lists best masses and uncertainties for combinations of 1 through 10 calibration disks. The particular combinations were chosen to keep the uncertainty associated with the total mass (approximately) as small as possible. Again, Eq. (1) was used to compute the listed uncertainties.

TABLE VI

LINEAR INTERPOLATION ANALYSIS (RUN E) MASS AND UNCERTAINTY ESTIMATES FOR SELECTED COMBINATIONS OF CALIBRATION D:SKS

Number

of Disks

1
2
3
4
5
6
7
8
9

10

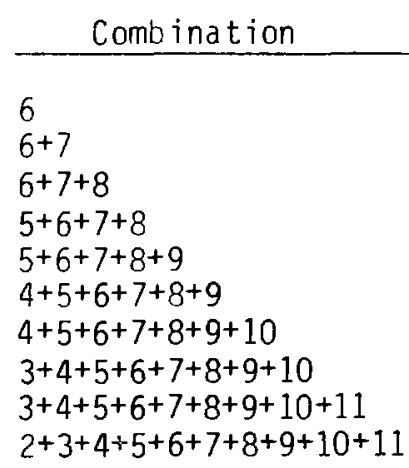

Mass Ur an iuni

(g)

278.21

553.45

829.24

1107.42

1383.76

1656.15

1931.89

2206.81

2482.92

2760.24
Relative

Uncertainty

(g)

Uncertainty

0.25012

0.899

0.42508

0.768

0.59983

0.723

0.74130

0.669

0.87726

0.634

1.00489

0.607

1.11906

0.579

1.23202

0.558

1. 34767

0.543

1.46084

0.529 


\section{Discussion}

We note that other methods of interpolation might also have been suggested. For example, the thick disks, rather than the thin, could easily have been chosen as a basis for evaluation, resulting in a slightly different method of interpolation. In general, such a scheme will produce best mass estimates with increased variance; however, interpolation error may be reduced, especially if longitudinal variation in ${ }^{235} \mathrm{U}$ content is pronounced. Thus, in view of the method adopted, any evidence of strong longitudinal fluctuation in 235 u content might be cause for concern. Figure 2 shows the mass values of Run $E$ plotted as a function of their initial positions along the ingot. The nonuniformity is large relative to the variances that result from the evaluation and suggests that the method chosen may have been inappropriate. In the case of the smooth and substantial longitudinal fluctuation in uranium content, regression procedures for estimating ${ }^{235} \mathrm{U}$ fraction as a polynomal function of position along the ingot may be most appropriate. Thick disk uranium content would then be obtained by integrating (averaging) the estimated

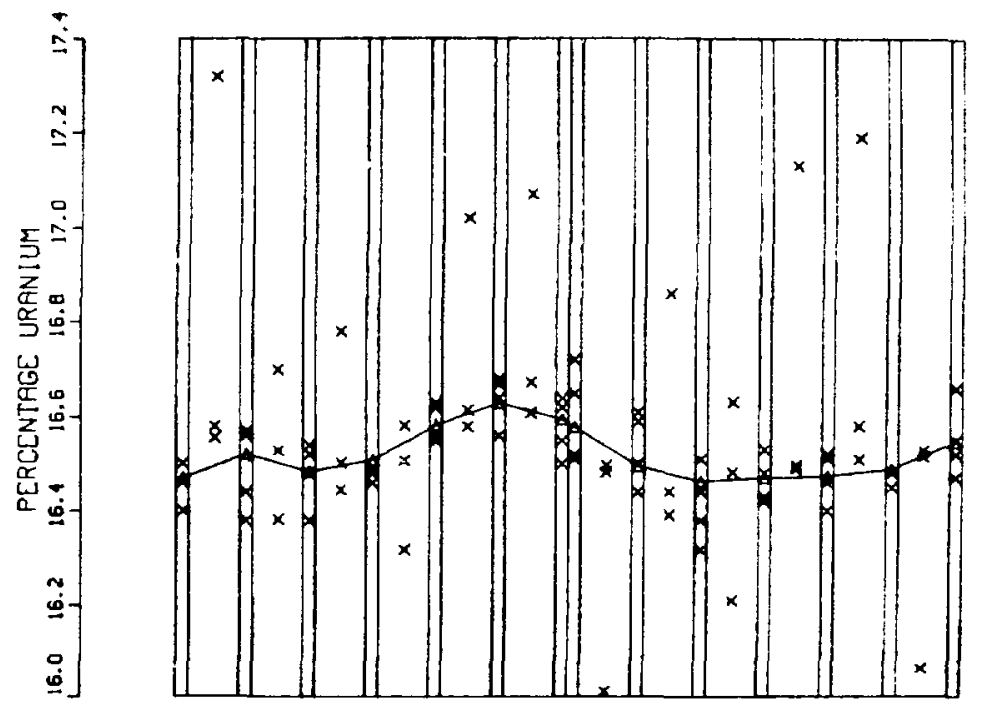

POSITION RLONG INGOT

Fig. 2. Run $E$ thin disk mass values plotted against position along ingot ( $\Delta=$ mass estimate; $x=$ measurement). 
polynomial over the curesponding subregions of the rod. We consider this approach in detail in the next section.

\section{A SECOND APPROACH: POLYNOMIAL INTERPOLATION}

A. Method

In the previous section, evidence for significant longitudinal fluctuation in ur anium content was found. Whereas no true physical model can be given to predict changes in uranium density, it was conjectured that polynomials ma be usefisl in describing them. In this section we consider the estimation of uranium fraction as an $i^{\text {th }}$ degree polynomial function, $p_{j}(x)$, of position $x$ along the ingot. Given the least squares estimate, $\hat{p}_{i}(x)$, of the polynomial, calibration mass values are found by integrating $\hat{p}_{i}(x)$ over the appropriate subregions of the log.

Briefly, the required least squares methodology is as follows. We assume that each observation $y_{j}\left(x_{j}\right)$, taken at $\log$ coordinate $x_{j}$, may be written

$$
\begin{aligned}
y_{j}\left(x_{j}\right) & =p_{j}\left(x_{j}\right)+e_{j} \\
& =\beta_{0}+\beta_{1} x_{j}+\beta_{2} x_{j}^{2}+\ldots+\beta_{i} x_{j}^{i}+e_{j} .
\end{aligned}
$$

Let $\because=\left(\beta_{0}, \ldots, \beta_{j}\right), \quad{\underset{\sim}{x}}_{j}^{\prime}=\left(1, x_{j}, x_{j}^{2}, \ldots, x_{j}^{i}\right), \quad x^{\prime}=\left(x_{i}, \ldots,{\underset{\sim}{n}}_{n}\right)$, $y^{\prime}=\left[y_{1}\left(x_{1}\right), \ldots, y_{n}\left(x_{n}\right)\right]$ and $e^{\prime}=\left(e_{1}, \ldots, e_{n}\right)$. Note that for the present analyses, none of the measurements, $y_{j}\left(x_{j}\right)$, are interpolated. Thus, the covariance of $y_{j}\left(x_{j}\right)$ and $y_{k}\left(x_{k}\right)$ is zero for $i \neq k$, and the variancecovariance matrix, $V$, of the data is diagonal with $V_{j j}=\operatorname{Var}\left[y_{j}\left(x_{j}\right)\right]=\sigma_{j}^{2}$. For a specified degree $i$, the least squares coefficients, $\beta_{0}, \ldots, \beta_{j}$, are chosen to minimize

$$
s^{2}=\underset{\sim}{e} V^{-1} \underset{\sim}{e} /[N-(i+1)]
$$

and are given by

$$
\hat{\beta}=\left(\underset{\sim}{x}{\underset{\sim}{v}}^{-1} x\right)^{-1} x_{\sim}^{\prime} \underline{\sim}^{-1} \underset{\sim}{y}
$$


The variance-covariance matrix of the estimated parameters is, in this case,

$$
C=\left(x^{\prime} v^{-1} x\right)^{-1} s^{2}
$$

Selection of a best order, $i$, for the model is accomplished by standard regression procedures and appropriate statistical tests (for examp'e, examination of all possible regressions, residual plots, and the use of the $F$, $R^{2}$, adjusted $R^{2}$ and $C_{p}$ statistics; see Refs. 7 and 8 for further discussion.)

Given $p_{j}(x)$, best calibration disk mass estimates and uncertainties are obtained simply. For example, assume that the jth calibration disk is bounded by $\log$ coordinates $a_{j}$ and $a_{j+1}$. Then the estimatod urani:im percentage, $f_{j}$, for the $j{ }^{\text {th }}$ disk is given by

$$
\begin{aligned}
& f_{j}=\int_{a_{j}}^{a+1} \hat{p}_{i}(x) d x /\left(a_{j+1}-a_{j}\right) \\
& =\left[\hat{\varepsilon}_{0} x+\ldots+\dot{\theta}_{i} x^{j+1} / i+1\right]_{j}^{a_{j}+1} /\left(a_{j+1}-a_{j}\right) \\
& =\sum_{k=1}^{i+1} a_{j, k} \hat{z}_{k-1}
\end{aligned}
$$

where

$$
\alpha_{j, k}=\left(a_{j+1}^{k}-a_{j}^{k}\right) /\left(a_{j+1}-a_{j}\right) .
$$

From Eq. (11),

$$
\operatorname{Var}\left(f_{j}\right)=\sum_{k=1}^{j+1} \sum_{i=1}^{i+1} \alpha_{j, l} c_{l, k} \alpha_{j, k} .
$$


Let $m_{j}$ denote the total mass of the $j^{\text {th }}$ calibration disk. Then $m_{j} f_{j} / 100$ is the uranium content and $m_{j} \dot{r}_{j}$ is the associated uncertainty, where the relative uncertainty, ${ }^{\prime} j$ is given by

$$
\tau_{j}=\frac{\operatorname{Nar}\left(\hat{f}_{j}\right)}{100}
$$

E. Evaluation

Before the regression analysis could hegin, we had to determine how to nandlo the relative data sets, 8 and 9 . ISets 4 and 6 were deleted as in the previous section.) Rather then attempt a nonlinear analys is such as described in Sec. I: , we adopted a simpler two-stage approach: Initially, we used only the absolite data sets $1, ?, 3$, and 5 to estimate the polynomial $p_{i}(x)$. from it we determined the average percentage, p, over the entire rod. We also computer! simple weighted averages, $w_{8}$ and $w_{q}$, of the eighth and $n i n t h$ data sets. Appropriate scale factors were then given by $R_{8}=w_{R} / P=0.9596$ and $c_{a}=w_{q} / p=n .149 h$. Note that these values are extremely close to thnse ind by the linear interpolation analysis, in which the $R_{8}$ and $R_{9}$ as: wates were 0.9599 and 0.1496 , respectively.) After scaling Sets 8 and 9 liv $R_{3}^{-1}$ and $R_{g}^{-?}$, respectively, we could treat all measurements as dbsolute. In the regression analyses that follow, ${ }_{j}$ coordinates range from $i+r .3(\mathrm{~mm} / 100)$, and measurements $y_{j}\left(x_{j}\right)$ are percentage uranium.

An excellent fit to the data was given by a 7 th-degree polynomial. We wed the computed Birge ratios as presented in Table VII, Regression $A$, to adjust the measurement uncertainties as described in Sec. III and carried out a new analysis, regression B. Again, a polynomial of degree 7 was appropriate. The new Birge ratios are presented in Table VII. For comparision, the Birge ratios of the final linear interpolation analysis are a) 50 given. Although found by completely different techniques, the two sets of Birge ratios are strikingly similar.

Tables VIII and IX sumarize the results of Regression $B$. Figure 2 iliustrates the fitted polynomial and the data from which it was estimated. In addition to the least squares coefficients, Table VIII presents best mass and uncertainty values for each of the calibration disks. Best masses and uncertainties for those combinations of thick disks specified in Sec. IV are given in Table IX. (Table $X$ presents the variance-covariance matrix of the parameters, used with Eq. (11) to compute the above uncertainties.) 18 
TABLE VII

BIRGE RATIOS FOR REGRESSION ANALYSES

ON DATA SETS $1,2,3,5,7,8$, and 9

ANO LINEAR INTERPOLATION ANALYSIS RUN E

Data Set

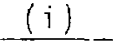

1

?

3

5

7

8

9

$B^{2}$

$s^{2}$

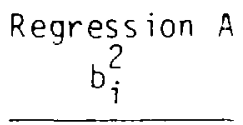

3.19

3.68

6.58

2. 22

0.97

1.26

4.51

3.27

3.27

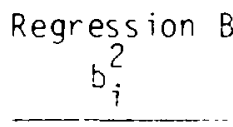

0.89

0.92

1. 32

1.01

0.99

0.91

0.7 ?

0.98

0.98

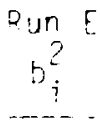

$r .93$

?. 86

1. 34

1.06

$? .00$

0.84

1.06

1.00

0.97

Enmparison with the results of the linear incerpolation analysis !Table VII shows that the two methods yield uranium mass estimates for the various combinations that are extremely close. The largest difference occurs when all 10 calibration disks are included and is only $0.66 \mathrm{~g}$ (2760.24g vs 2760.90g). The uncertainties produced by the polynomial andysis are generally less than 80 of those associated with the linear analysis. The question thus arises as to which set of results should be used. We consider this question in detail in the following section.

VI. A COMPARISON OF THE LINEAR ANO POLYNOMIAL APPROACHES

Each of the methods described in the previous two sections can be criticized on separate grounds. The linear interpolation scheme, for example, may tend to underestimate longrtudinal fluctuation, as noted previously. In contrast, with the polynomial approach, the possibility of overestimating variation in uranium density must be considered. As an extreme example, a 25 thdegree polynomial could, of course, be constructed to intersect the weighted averages of the observations at each of the 26 (14 thin- and 12 thick-disk) points of support along the ingot. Clearly, the sinusoidal character of such a polynomial would very likely cause the interpolated estimates of thick disk ur an ium content to be significantly in error. 
TABLE VIII

REGRESSION B ${ }^{a}$ CALIBRATION DISK MASS AND UNCERTAINTY ESTIMATES

\begin{tabular}{|c|c|c|c|c|c|}
\hline$s k$ & $\begin{array}{c}\text { Tota! } \\
\text { Mass } \\
\text { !g! }\end{array}$ & $\begin{array}{c}\text { Percen tage } \\
\text { Ur an ium }\end{array}$ & $\begin{array}{c}\text { Mass } \\
\text { Ur anium } \\
\quad(\mathrm{g}) \\
\end{array}$ & $\begin{array}{l}\text { Uncertainty } \\
-(g)\end{array}$ & $\begin{array}{c}\text { Relative } \\
\text { Uncertainty } \\
\left(\times 10^{-3}\right) \\
\end{array}$ \\
\hline $\begin{array}{l}\vdots \\
? \\
3 \\
5 \\
5 \\
\vdots \\
\vdots \\
\vdots \\
1 !\end{array}$ & $\begin{array}{l}1671.13 \\
1680.6 ? \\
1666.62 \\
1546.30 \\
1675.13 \\
1674.66 \\
1664.07 \\
1673.59 \\
1679.23 \\
1674.02 \\
1675.35 \\
1679.96\end{array}$ & $\begin{array}{l}16.539 \\
16.503 \\
16.491 \\
16.556 \\
16.619 \\
16.618 \\
16.542 \\
10.477 \\
16.459 \\
16.479 \\
16.492 \\
15.503\end{array}$ & $\begin{array}{l}276.40 \\
277.35 \\
274.84 \\
272.56 \\
278.38 \\
279.29 \\
275.34 \\
275.76 \\
276 . ? 1 \\
275.86 \\
276.30 \\
? 76.06\end{array}$ & $\begin{array}{l}0.29208 \\
0.23928 \\
0.22515 \\
0.20851 \\
0.21717 \\
0.20174 \\
0.20360 \\
0.21772 \\
0.21785 \\
0.25220 \\
0.25220 \\
0.26701\end{array}$ & $\begin{array}{l}1.057 \\
0.863 \\
0.819 \\
0.765 \\
0.780 \\
0.725 \\
0.739 \\
0.791 \\
0.789 \\
0.914 \\
0.913 \\
0.967\end{array}$ \\
\hline
\end{tabular}

\section{TABLE IX}

REGRESSION B MASS AND UNCERTAINTY ESTIMATES FOR

SELECTED COMBINATIONS OF CALIBRATION DISKS

\begin{tabular}{clrrr}
$\begin{array}{c}\text { Number } \\
\text { of Disks }\end{array}$ & \multicolumn{1}{c}{ Combination } & $\begin{array}{c}\text { Urass } \\
(\mathrm{g})\end{array}$ & $\begin{array}{c}\text { Uncertainty } \\
(\mathrm{g})\end{array}$ & $\begin{array}{c}\text { Relative } \\
\text { Uncertainty } \\
\left(\mathrm{x} 10^{-3}\right)\end{array}$ \\
\cline { 1 - 2 } 1 & 6 & 278.29 & 0.20176 & 0.725 \\
2 & $6+7$ & 553.63 & 0.35790 & 0.647 \\
3 & $6+7+8$ & 829.39 & 0.50238 & 0.606 \\
4 & $5+6+7+8$ & 1107.78 & 0.58913 & 0.532 \\
5 & $5+6+7+8+9$ & 1383.99 & 0.67445 & 0.487 \\
6 & $4+5+6+7+8+9$ & 1656.55 & 0.74722 & 0.451 \\
7 & $4+5+6+7+8+9+10$ & 1932.41 & 0.84151 & 0.436 \\
8 & $3+4+5+6+7+8+9+10$ & 2207.25 & 0.90680 & 0.411 \\
9 & $3+4+5+6+7+8+9+10+11$ & 2483.55 & 0.97838 & 0.394 \\
10 & $2+3+4+5+6+7+8+9+10+11$ & 2760.90 & 1.02622 & 0.372
\end{tabular}


TABLE $X$

VAR: ANCE-COVAR IANCE MATRIX OF ESTIMATED PARAMETERS OF REGRESSION Ba

\begin{tabular}{|c|c|c|c|c|c|c|c|}
\hline & $\cdots$ & & $\underline{3}$ & $\ldots \ldots \ldots$ & $\ldots \ldots-$ & $\cdots-$ & $\ldots \ldots \ldots$ \\
\hline$\vdots$ & $\therefore-$ & $\stackrel{7}{-2}$ & $\Delta$ & $\cdots-$ & 6 & $\cdots$ & $-P$ \\
\hline$\therefore 57 ?$ & 34. ก9?: & 18.7116 & 85.7385 & 40.4714 & !h. 368 ! & $7.75: 7$ & $0.188 !$ \\
\hline $35.09 ?$ : & $11120.900 !$ & 3655.4900 & 5115.5600 & 3529.7700 & 1279.2300 & 2730335 & $16.947=$ \\
\hline 79.7775 & $3645,595 \times 1$ & $14,83.0000$ & 20935.9000 & 14876.8000 & 5s,ok. hor & ingn. $97 n$ & $\therefore 4,9 ? 74$ \\
\hline 85,1385 & $5 ! ! 6,560)$ & -20935.9000 & 31555.5000 & ?2858. & Q4 $80 ., 10 \%$ & 16019.05 & $\because .9530$ \\
\hline 50.4214 & 3528.7700 & 14876.8000 & ??85R.6000 & $1679.300 n$ & 6??ח. 2 . & ing. & 89.7399 \\
\hline :6. $368 ?$ & 1279.2300 & 5505.7600 & วน 80.3100 & $63 / r$. 'Rn & $43 ? .030$ & $463.808 \Omega$ & 34.7566 \\
\hline 2.7577 & 273.6330 & 1970.9700 & $16 \cap 8.417 n$ & $13 n 4.21 x$ & Af? angil & $0 p .762 F$ & f. 6P?: \\
\hline ก. 1821 & :6. $94 / 5$ & 74.9274 & $\because 19.7530$ & 89.700 & 36. :Lh & F. $6.93 \%$ & 7. G06: \\
\hline
\end{tabular}

The followino procedure was devised to qauge the re'ative accuracies of the two procedures. Thick disk ur anium masses were first est mated ry each of the methods without the use of the wol ithick disk: measuraments. Through the use of the PRESS lpredicted residual sum of squares) statistic, we then determined which of the methor could better predict the deleted calibration disk measurements. Let $y_{i j}$ be the $j^{\text {th }}$ measurement on the $i^{\text {th }}$ calibration disk ${ }^{\prime} i=1, \ldots, 12, j=1,2,31$ and let, $;$ be the uncertainty associated with $y_{i j}$, By $f_{i}^{\prime}$ and $f_{i}^{p}$ denote the estimated uranium percentages for the $i^{\text {th }}$ calibration disk as determined by the linear and polynomial analyses, respectively. Then our procedure is to compare PRESS, with PRESS where

$$
\begin{aligned}
& \text { PRESS }_{1}=\sum_{i=1}^{12} \sum_{j=1}^{3}\left[\frac{\left(f_{i}^{1}-y_{i j}\right)}{\sigma_{i j}}\right]^{?} \\
& \text { PRESS }_{P}=\sum_{i=1}^{12} \sum_{j=1}^{3}\left[\frac{\left(f_{i}^{p}-y_{i j}\right)}{\sigma_{i j}}\right]^{2} .
\end{aligned}
$$

Smaller PRESS values indicate better prediction efficiency. 
The results of the linear and polynomial analyses are plotted in Figs. 3 and 4. In Fig. 3, best thin disk uranium percentage estimates, as determined by the linear analysis, are plotted and, to reflect the linear interpolations performed to obtain calibration disk estimates, are connected with straight lines. The fitted polynomial, again of degree 7 , is plotted in Fig. 4 . Note that the polynomial seems unstable at each end of the log. In particular, the lump centered over the left-most calibration jisk appears to be unjustified and, at first glance, may mean that the polynomial is overestimating longitudinal flux in that region. Surprisingly, however, this is not the case. The NDA measurements taken from the left-most thick disk indicate that an increase in $235 U$ content, as predicted by the polynomial, does, in fact, occur (see Fig. 2). This leads to a reduction in PRESS relative to PRESS, and, as indicated by the computed values of the PRESS statistics

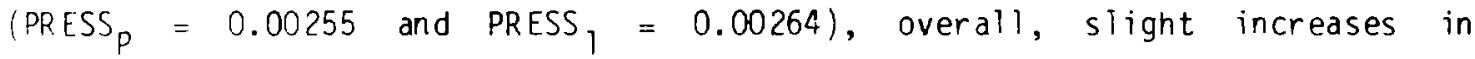
accuracy may be attributed to the polynomial approach.

VII. CONCLUSIONS

Figure 5 illustrates the results of the linear and polynomial analyses. Th in disk uranium percentages, as determined by Run $E$ in Sec. IV, are plotted and connected by straight lines. Superimposed on this linear spline is the seventh degree polynomial upon which the calibration disk mass estimates of Sec. $V$ were based. The results show substantial agreements, especially for those calibration disks (2 through 11) to be used with the Shuffler. However, un the basis of the comparisons carried out in Sec. VI, the polynomial approach is preferred. Although slightly less conservative in terms of the uncertainty estimates provided, as indicated by the PRESS analysis of the preceding section, the method seems to more accurately characterize the longitudinal variation in $225 \mathrm{U}$ density that occurs. 


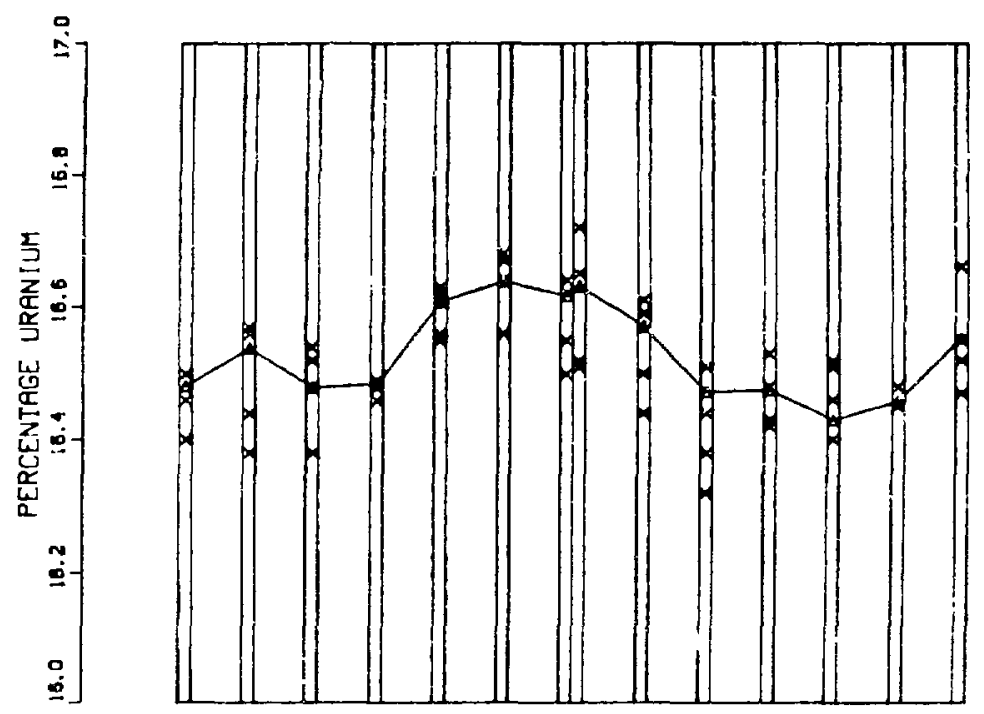

PDSITION ALONG INGOT

Fig. 3. Best thin disk mass values plotled against position along ingot; linear analysis--NDA measurements excluded ( $\Delta=$ mass estimate; $x=$ meac urement).

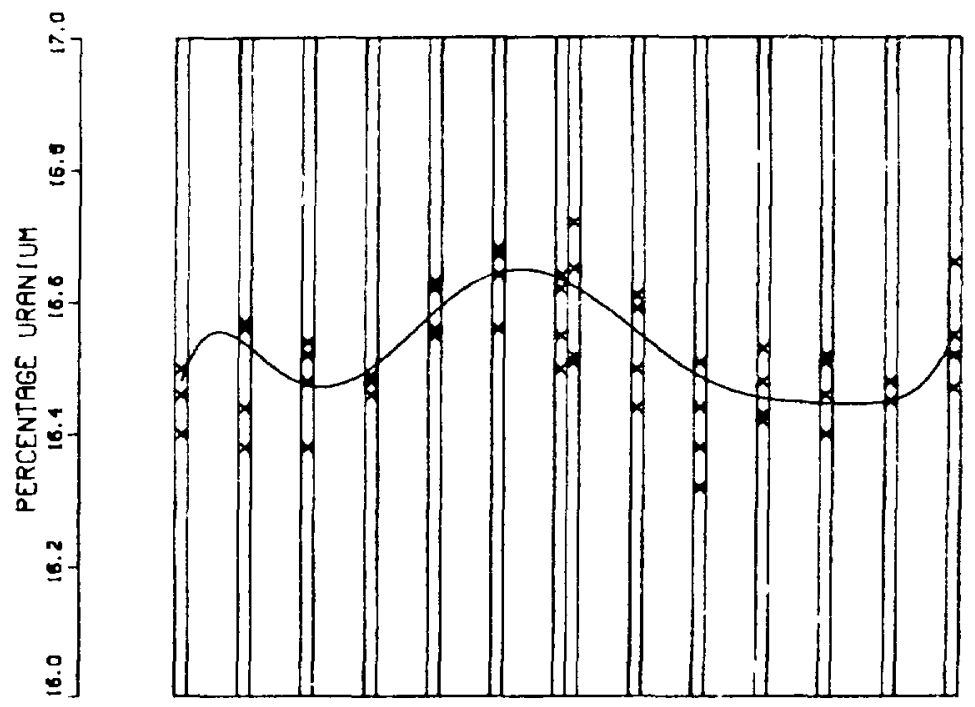

POSITION ALONG INGOT

Fig. 4. Polynomial estimate of percentage uranium content as a function of position along ingot; polynomial analysis--NDA measurements excluded $(x=$ measurement). 


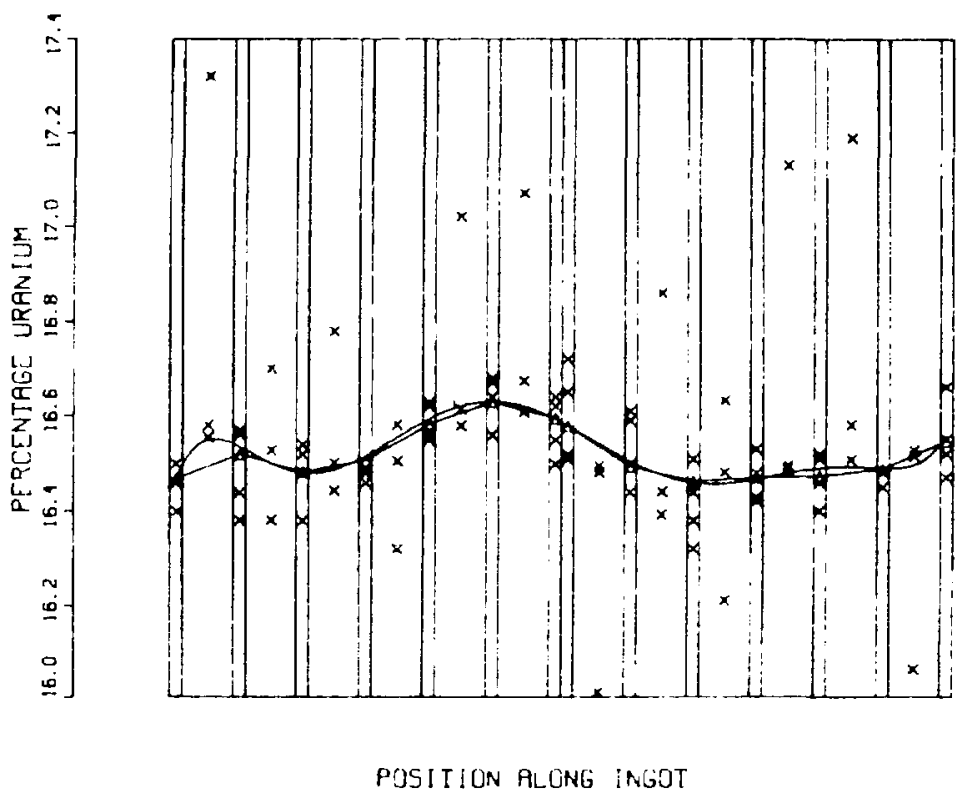

Fig. 5. Run E linear spline and Regression B polynomial estimates of uranium density vs position along ingot $[\Delta$ - best thin disk estimate from linear (spline) analysis; $y=$ measurement]. 


\section{ACKNOWLEDGMENTS}

The authors would like to thank Dick Beckman of the Statistics Group at Los Alamos and Dennis Cook of the University of Minnesota for helpful suggestions.

\section{REFERENCES}

1. T. W. Crane, "Test and Evaluation Results of the $252 \mathrm{Cf}$ Shuffler at the Savannah River Plant," Los Alamos National Laboratory unpublished data, 1980.

2. A. Gibbs and S. P. Boynton, "Uranium Standards for Californium Shuffler," E. I. du Pont de Nemours and Company, Savannah River Plant report n?SPU 78-11-19 (October 1978).

3. A. G. Sapanora, D. D. Jackson, S. F. Marsh, M. R. Betts, and D. J. Hoara, "Automated Spectrophotometer and Isotope Dilution Mass Spectrometry Analytical Results for the SRP Standards Material," Los Alamos National Laboratory, Analytical Chemistry Group report NB21643 (March 13, 1979).

4. T. D. Reilly, "Gamma Spectroscopic Examination of SRP Test Materials" (Q-1-78-731), Los Alamos National Laboratory memorandum to $T$. W. Crane (September 27, 1978).

5. "Standards for the SRP Shuffler" and "Garma-Ray Measurements of SRP Shuffler Materials," in "Nuclear Safeguards Research and Development Program Status Report, September-December 1978," S. D. Gardner, Ed., Los Alamos National Laboratory report LA-7706-PR (May 1979), pp. 15-18.

6. B. N. Taylor, W. H. Parker, and D. N. Langenberg, The Fundamental Constants and Quantum Electrodynamics (Academic Press, New York, 1969).

7. N. R. Draper and H. Smith, Applied Regression Analys is (John Wiley and Sons, Inc., New York, 1966).

8. S. Weisberg, Multreg Users Manual (Department of Applied Statistics, University of Mirnesota, St. Paul, 1980.) 